TITLE:

\title{
Fabrication of TiAl3 coating on TiAl- based alloy by Al electrodeposition from dimethylsulfone bath and subsequent annealing
}

\section{AUTHOR(S):}

Miyake, Masao; Tajikara, Seiya; Hirato, Tetsuji

\section{CITATION:}

Miyake, Masao ... [et al]. Fabrication of TiAl3 coating on TiAl-based alloy by Al electrodeposition from dimethylsulfone bath and subsequent annealing. Surface and Coatings Technology 2011, 205(21-22): 5141-5146

\section{ISSUE DATE:}

2011-08

URL:

http://hdl.handle.net/2433/143597

\section{RIGHT:}

(C) 2011 Elsevier B.V.; This is not the published version. Please cite only the published version.; この論文は出版社版でありません。引用の際に は出版社版をご確認ご利用ください。 
Fabrication of $\mathrm{TiAl}_{3}$ coating on TiAl-based alloy by $\mathrm{Al}$ electrodeposition from dimethylsulfone bath and subsequent annealing

Masao Miyake, Seiya Tajikara, Tetsuji Hirato*

Graduate School of Energy, Kyoto University

Yoshida-hommachi, Sakyo-ku, Kyoto 606-8501, Japan

* Address correspondence to: Prof. T. Hirato

hirato.tetsuji.2n@kyoto-u.ac.jp

$+81-75-753-5432$

\section{Abstract}

$\mathrm{TiAl}_{3}$ coating was formed on TiAl alloy by $\mathrm{Al}$ electrodeposition from a dimethylsulfone $\left(\mathrm{DMSO}_{2}\right)$ bath and subsequent annealing. Before the $\mathrm{Al}$ electrodeposition, anodic dissolution of TiAl substrate in the $\mathrm{DMSO}_{2}$ bath was conducted to remove the surface oxide layer of the TiAl substrate. By performing the $\mathrm{Al}$ electrodeposition immediately after the anodic dissolution, uniform $\mathrm{Al}$ films adherent to the TiAl substrate could be obtained. Annealing at $650-1000{ }^{\circ} \mathrm{C}$ yielded a single $\mathrm{TiAl}_{3}$ layer or two layers of $\mathrm{TiAl}_{3}$ and $\mathrm{TiAl}_{2}$ on the TiAl substrate. The resulted $\mathrm{TiAl}_{3}$ layer was confirmed to show oxidation-resistance at high temperatures.

\section{Keywords}

Electroplating, Organic solvent, Aluminide, Intermetallics, Diffusion 


\section{Introduction}

TiAl-based alloys have great potential for high-temperature structural applications such as turbine blades of internal-combustion engines, owing to their high specific strength and high creep resistance at elevated temperatures [1-3]. However, the TiAl alloys suffer heavy oxidation at high temperatures over $700{ }^{\circ} \mathrm{C}$, because they do not form the long-lasting protective $\mathrm{Al}_{2} \mathrm{O}_{3}$ scale, but rather a nonprotective $\mathrm{TiO}_{2}+\mathrm{Al}_{2} \mathrm{O}_{3}$ mixed scale [4-6]. Thus, a surface finishing is required to improve the oxidation resistance without altering the bulk properties. Unlike $\mathrm{TiAl}$ or $\mathrm{Ti}_{3} \mathrm{Al}$, the $\mathrm{Al}$-rich intermetallic, $\mathrm{TiAl}_{3}$, is capable of forming the protective $\mathrm{Al}_{2} \mathrm{O}_{3}$ scale, and therefore $\mathrm{TiAl}_{3}$ is often employed as an oxidation-resistant coating. Various processes to form the $\mathrm{TiAl}_{3}$ coating on the TiAl based alloys have been studied, including pack cementation [6-8], hot-dip coating [9-11], arc melting [12], electro-spark deposition [13], sputtering [14-16], and thermal spray coating [17]. In this paper, we propose a process composed of $\mathrm{Al}$ electrodeposition on the TiAl alloys and subsequent annealing for the formation of $\mathrm{TiAl}_{3}$ layer through interdiffusion. This approach using electrodeposition has advantages over the aforementioned processes in that the thickness of the coating can be controlled easily, the coating can be formed even on surfaces with complex shapes, and the process cost is low.

Electrodeposition of $\mathrm{Al}$ does not occur in an aqueous solution, and thus requires a non-aqueous medium as an electrolytic bath. We used a dimethylsulfone $\left(\mathrm{DMSO}_{2}\right)-\mathrm{AlCl}_{3}$ bath [18]. The merits of this electrolyte are that uniform $\mathrm{Al}$ films can be electrodeposited at high rates at around room temperature [19], problematic vaporization of $\mathrm{AlCl}_{3}$ is suppressed because $\mathrm{DMSO}_{2}$ coordinates to $\mathrm{Al}$ ions and stabilizes them, and furthermore this electrolyte is much less expensive than the room temperature molten salts studied for Al electrodeposition [20, 21].

In this work, we studied the formation of $\mathrm{TiAl}_{3}$ coating on a $\mathrm{TiAl}$ substrate by electrodeposition of $\mathrm{Al}$ from the $\mathrm{DMSO}_{2}$ bath and subsequent annealing to demonstrate the feasibility of this process. In general, electrodeposited films do not adhere well to $\mathrm{Ti}-\mathrm{Al}$ alloys because $\mathrm{Ti}-\mathrm{Al}$ alloys have a natural oxide layer on their surfaces [22]. To remove the oxide layer and to obtain an $\mathrm{Al}$ layer adhering to the TiAl substrate, anodic dissolution of the TiAl substrate was conducted in the $\mathrm{DMSO}_{2}$ bath prior to the $\mathrm{Al}$ electrodeposition. By performing the $\mathrm{Al}$ electrodeposition immediately after 
the anodic dissolution, the $\mathrm{Al}$ layer can be electrodeposited on the bare surface of the TiAl substrate, securing sufficient adhesion to the substrate. After the $\mathrm{Al}$ electrodeposition, annealing to form the $\mathrm{TiAl}_{3}$ layer was conducted in the temperature range from $650{ }^{\circ} \mathrm{C}$ to $1000^{\circ} \mathrm{C}$.

\section{Experimental procedures}

\subsection{Materials}

The TiAl alloy substrate was prepared from a Ti-47 at.\% $\mathrm{Al}$ ingot which has a lamellar structure composed of $\gamma$-TiAl and $\alpha_{2}-\mathrm{Ti}_{3} \mathrm{Al}$ phases. The ingot was sliced into plates with a thickness of about $0.6 \mathrm{~mm}$. The surface of the alloy plate was polished with $\mathrm{SiC}$ papers, and the plate was immersed in $10 \%$ oxalic acid at $80{ }^{\circ} \mathrm{C}$ for $60 \mathrm{~min}$. After rinsing in distilled water and drying, a part of the TiAl plate was covered with PTFE tape so that only a certain area (10 $\mathrm{mm}$ squared) would be exposed. The TiAl plate had been dried at $60^{\circ} \mathrm{C}$ for $24 \mathrm{~h}$ under a reduced pressure prior to use.

The electrolyte for $\mathrm{Al}$ electrodeposition was prepared in an Ar-filled glove box equipped with a circulation system. $\mathrm{DMSO}_{2}$ (Tokyo Chemical Industry, 99\%) and $\mathrm{AlCl}_{3}$ (Fluka, anhydrous, 99\%) were used as the solvent and $\mathrm{Al}$ source, respectively. Dimethylamine hydrochloride $\left(\left(\mathrm{CH}_{3}\right)_{2} \mathrm{NH}_{2} \mathrm{Cl}\right.$, Sigma-Aldrich, 99\%) was added to the electrolyte to inhibit the inclusion of impurities such as sulfur and chlorine to the electrodeposited Al layer. The $\mathrm{DMSO}_{2}$ and the dimethylamine hydrochloride were used after drying for 24 $\mathrm{h}$ at $60{ }^{\circ} \mathrm{C}$ and $120{ }^{\circ} \mathrm{C}$, respectively. $\mathrm{AlCl}_{3}$ had been stored in the glove box and was used as received. The mol ratio of $\mathrm{DMSO}_{2}$ to $\mathrm{AlCl}_{3}$ to dimethylamine hydrochloride of the electrolytic bath was $10: 2: 0.1$.

\subsection{Anodic Dissolution and Electrodeposition}

The anodic dissolution of the TiAl substrate and the electrodeposition of Al layer were performed in the Ar-filled glove box. A glass vessel with a volume of $150 \mathrm{~mL}$ was used as an electrochemical cell. The TiAl plate described above and an $\mathrm{Al}$ plate (Nilaco, 99\%) were used as the working and counter electrodes, respectively. As a reference electrode, an $\mathrm{Al}$ wire immersed in a mixture of $\mathrm{DMSO}_{2}$ and $\mathrm{AlCl}_{3}$ with a ratio of $10: 2$ was employed. The anodic dissolution and the electrodeposition were carried out with an electrochemical analyzer (ALS, model $660 \mathrm{C}$ ). The temperature of the electrolyte was maintained at $110{ }^{\circ} \mathrm{C}$ by a thermostat. The electrolyte 
was stirred by a magnetic stirrer at $80 \mathrm{rpm}$ during the electrochemical reactions. The anodic polarization curve was measured at the scan rate of 10 $\mathrm{mV} \mathrm{s}^{-1}$.

\subsection{Annealing}

The TiAl substrate covered with the electrodeposited Al layer was annealed in a vacuum $(<0.4 \mathrm{~Pa})$ pulled by a diffusion pump. The annealing temperatures were varied in the range from 650 to $1000{ }^{\circ} \mathrm{C}$. The samples were first heated to the annealing temperatures from ambient temperature in an hour, and then kept at the annealing temperatures for an hour. Finally, they were slowly cooled in the furnace.

\subsection{Characterization}

Samples were investigated by X-ray diffraction (XRD, PANalytical, X'Pert PRO-MPD) and scanning electron microscope (SEM, Hitachi S-3500) equipped with an energy dispersive X-ray spectrometer (EDX). XRD was measured from the surface of the sample. For cross-sectional observation by SEM, samples were cut and polished with diamond paste $(1 \mu \mathrm{m})$ followed by ultrasonic cleaning.

\section{Results and discussion}

\subsection{Anodic dissolution of TiAl substrate as pretreatment}

$\mathrm{Al}$ layers electrodeposited on the $\mathrm{TiAl}$ substrate without pretreatment did not show sufficient adhesion to the substrate and easily delaminated. The poor adhesion would be due to the natural oxide layer on the TiAl substrate. Cleaning of the substrate in $10 \%$ oxalic acid was not effective; although the oxide layer can be dissolved away in the acid, surface oxidation of the TiAl substrate occurs again as soon as the substrate contacts air. In order to remove the oxide layer completely and to make it possible to deposit $\mathrm{Al}$ layer onto the bare TiAl surface, the TiAl substrate was anodically dissolved in the $\mathrm{DMSO}_{2}$ bath.

The anodic polarization curve for the TiAl substrate in the $\mathrm{DMSO}_{2}$ bath (Fig. 1) was first taken to elucidate the dissolution behavior. When the potential of the substrate was scanned from the open circuit potential $(0.47$ V) to the anodic direction, anodic current was observed at above $0.5 \mathrm{~V}$. Since the anodic decomposition of the $\mathrm{DMSO}_{2}$ bath does not occur until $2.5 \mathrm{~V}$ [23], 
this anodic current must be due to the dissolution of the TiAl substrate. No sign of passivation was observed in this measurement range, unlike the case of the $\mathrm{AlCl}_{3}-\mathrm{NaCl}-\mathrm{KCl}$ bath where TiAl is passivated by the formation of $\mathrm{TiCl}_{3}$ layer [24]. This indicates that the solubility of $\mathrm{TiCl}_{3}$ is higher in the $\mathrm{DMSO}_{2}$ bath than in the $\mathrm{AlCl}_{3}-\mathrm{NaCl}-\mathrm{KCl}$ system.

Figure 2 shows the morphology of the surface of the TiAl substrate after the anodic dissolution at $0.8,1.4$ and $2.0 \mathrm{~V}$ for $30 \mathrm{C} \mathrm{cm}^{-2}$. The SEM observation confirmed that the dissolution occurred all over the surface of the substrate at all the potentials, but the morphologies resulting from the dissolution differed with potential. The dissolution at 0.8 and $1.4 \mathrm{~V}$ generated a rough stripe pattern corresponding to the lamellar structure of the TiAl substrate (Figs. 2a and b). EDX analysis revealed that the $\mathrm{Al}$ content of the part where the dissolution proceeded more was 49 at.\%, while that of the less dissolved part was 31 at.\%, indicating that the TiAl phase dissolved faster than $\mathrm{Ti}_{3} \mathrm{Al}$ from the lamellar structure (inset in Fig. 2a). In contrast, the dissolution at $2.0 \mathrm{~V}$ (Fig. 2c) produced a morphology unrelated to the lamellar structure, implying that the dissolution rates of the TiAl and $\mathrm{Ti}_{3} \mathrm{Al}$ phases were almost the same at this potential. The reason for the evolution of the characteristic morphology is not clear. However, active dissolution of the TiAl substrate surely occurs at the potentials over $0.8 \mathrm{~V}$ and thus the bare surface of the TiAl substrate without the oxide layer can be exposed to the electrolyte.

Figure 3 shows the variation of the dissolution current of the TiAl substrate with time at $2 \mathrm{~V}$. The dissolution current increased steeply at the beginning of the polarization and became $40 \mathrm{~mA} \mathrm{~cm}^{-2}$ in $10 \mathrm{sec}$. The current then increased gradually and reached a constant value of $50 \mathrm{~mA} \mathrm{~cm}^{-2}$ after about $150 \mathrm{sec}$. The initial low current implies that the surface oxide layer prevents the active dissolution of the TiAl substrate. Because the oxide layer disappears as the dissolution proceeds, the dissolution current increases with time. Thus, the oxide layer seems to have been completely removed when the current density reached the constant value in $150 \mathrm{sec}$. The amount of electrical charge used for the anodic dissolution until $150 \mathrm{sec}$ was about 6.7 $\mathrm{C} \mathrm{cm}^{-2}$. Anodic dissolution as a pretreatment for the TiAl substrate was carried out thereafter at $2 \mathrm{~V}$ for $10 \mathrm{C} \mathrm{cm}^{-2}$, ensuring complete removal of the surface oxide layer. It should be noted that the polarization curve of Fig. 1 was also taken after this anodic dissolution was performed to remove the 
surface oxide layer. If the substrate was covered with oxide, a smaller current would be observed.

\subsection{Electrodeposition of Al layer}

An Al layer firmly adhering to the TiAl substrate could be obtained by performing galvanostatic electrodeposition at $120 \mathrm{~mA} \mathrm{~cm}^{-2}$ for $1000 \mathrm{sec}$ after the anodic dissolution of the TiAl substrate. XRD analysis confirmed that the electrodeposited layer was composed of metallic Al (Fig. 4). Figure 5 shows a cross-sectional SEM image of the electrodeposited sample together with composition profile measured by EDX, indicating the formation of a dense, uniform Al layer with a thickness of about $40 \mu \mathrm{m}$. The current efficiency for the Al electrodeposition can be estimated to be almost $100 \%$ from the thickness of the Al layer. The SEM image also reveals the rough interface and a small crack between the $\mathrm{Al}$ layer and the TiAl substrate. The presence of the crack, which seems to have been caused during the sample preparation for the cross-sectional observation, suggests that the adhesion of the $\mathrm{Al}$ layer to the substrate is still not very high. However, the adhesion is strong enough to prevent the Al layer from delamination. The rough surface of the substrate should have been caused by the anodic dissolution. Such a rough surface strengthens the adhesion of the electrodeposited layer by the anchor effect. Anodic dissolution therefore seems to contribute to the enhancement of the adhesion in two ways: removal of the oxide layer and roughening the surface of the substrate. Chu and Wu reported that sputtered Al films on TiAl substrate spalled out from the substrate when the thickness of the $\mathrm{Al}$ film was over $5 \mu \mathrm{m}$ [16]. In contrast, dense Al films with a thickness of more than $40 \mu \mathrm{m}$ could be obtained by electrodeposition.

\subsection{Formation of $\mathrm{TiAl}_{3}$ layer by annealing}

The TiAl substrate with the electrodeposited Al layer was annealed at 650,700 and $1000{ }^{\circ} \mathrm{C}$ to form a $\mathrm{TiAl}_{3}$ layer through interdiffusion. Figure 6 shows XRD patterns of the samples after the annealing. In the pattern of the sample annealed at $650{ }^{\circ} \mathrm{C}$, which is lower than the melting point of $\mathrm{Al}$ $\left(660{ }^{\circ} \mathrm{C}\right)$, diffractions of $\mathrm{Al}$ and $\mathrm{TiAl}_{3}$ were detected. The surface of this sample kept its silver-white appearance even after the annealing, indicating that a part of the electrodeposited $\mathrm{Al}$ remained at the surface without diffusing to form intermetallic compounds. In contrast, the surface of the 
samples turned to silver-gray by the annealing at higher temperatures $\left(700{ }^{\circ} \mathrm{C}\right.$ and $1000{ }^{\circ} \mathrm{C}$ ). The XRD patterns of these samples showed only the diffraction peaks of $\mathrm{TiAl}_{3}$, indicating absence of the unreacted $\mathrm{Al}$ layer.

Figure 7 shows SEM images and composition profiles of the cross-sections of the annealed samples. Although the sample annealed at $650^{\circ} \mathrm{C}$ had an unreacted $\mathrm{Al}$ layer on the surface, this fell off when the sample was cut for the cross-sectional observation. The unreacted Al layer therefore cannot be seen in the SEM image (Fig. 7a). The SEM image, however, confirmed the formation of an intermetallic compound layer. The composition of the layer was determined by EDX to be 75 at.\% $\mathrm{Al}$ and 25 at.\% Ti, indicating that the produced compound was $\mathrm{TiAl}_{3}$. This is in agreement with the XRD analysis (Fig. 6a). The annealing at the temperature lower than the melting point of $\mathrm{Al}$ could generate the $\mathrm{TiAl}_{3}$ layer by solid-state diffusion, but the one-hour annealing at this temperature was too short for the $40-\mu \mathrm{m}$-thick Al layer to fully react with the TiAl substrate. In contrast, the whole Al layer diffused to form intermetallic compounds at the higher temperatures. The cross-section of the sample annealed at $700{ }^{\circ} \mathrm{C}$ showed the formation of a single phase of $\mathrm{TiAl}_{3}$ on the TiAl substrate (Fig. 7b). The annealing at $1000{ }^{\circ} \mathrm{C}$ yielded an additional compound layer between the surface $\mathrm{TiAl}_{3}$ layer and the TiAl substrate (Fig. 7c). Judging from the composition, the additional layer should be $\mathrm{TiAl}_{2}$ phase. Because the $\mathrm{TiAl}_{2}$ phase existed behind the $\mathrm{TiAl}_{3}$ layer with the thickness of $30 \mu \mathrm{m}$, it is reasonable that the XRD patterns taken from the surface of the sample did not detect the $\mathrm{TiAl}_{2}$ phase. In the $\mathrm{TiAl}_{3}$ layer, formation of some voids was observed. These voids could be caused by flux imbalance between the slowly diffusing $\mathrm{Ti}$ and rapidly diffusing $\mathrm{Al}$ [25]. The void formation was less pronounced in the sample annealed at the lower temperatures.

\subsection{Oxidation test}

The TiAl substrate, a part of which was coated with the $\mathrm{TiAl}_{3}$ layer through the process with the annealing at $700{ }^{\circ} \mathrm{C}$, was heated in air at $1100{ }^{\circ} \mathrm{C}$ for an hour to verify the oxidation-resistance of the $\mathrm{TiAl}_{3}$ coating. By the heating in air, the uncoated area of the TiAl substrate turned to white, while the coated area did not change its silver-gray appearance. The cross-sectional SEM image of the uncoated part revealed that a thick oxidation layer (about $60 \mu \mathrm{m}$ ) grew on the $\mathrm{TiAl}_{3}$ substrate (Fig. 8). EDX 
analysis of the points marked in Fig. 8 suggested that the oxide layer consisted of an outer $\mathrm{TiO}_{2}$ layer, and an $\mathrm{Al}_{2} \mathrm{O}_{3}$ and $\mathrm{TiO}_{2}$ mixed-oxide layer (Table 1), as has frequently been described in the literature (see, e.g. Ref [6]). In contrast, the cross sectional SEM image and composition profile of the part with the $\mathrm{TiAl}_{3}$ coating showed that the $\mathrm{TiAl}_{3}$ phase was still present as the dominant phase, although an additional phase of $\mathrm{TiAl}_{2}$ emerged by the progress of the diffusion at $1100{ }^{\circ} \mathrm{C}$ (Fig. 9). The composition profile also revealed an enrichment of $\mathrm{Al}$ at the surface of the $\mathrm{TiAl}_{3}$ layer. The $\mathrm{Al}$ enrichment is attributed to the generation of $\mathrm{Al}_{2} \mathrm{O}_{3}$ by preferential oxidation of the $\mathrm{TiAl}_{3}$ layer [6]. The $\mathrm{Al}$ enrichment was only observed at the vicinity of the surface, and thus this surface $\mathrm{Al}_{2} \mathrm{O}_{3}$ layer seems to have suppressed the progress of the oxidation. This result is consistent with the reports on $\mathrm{TiAl}_{3}$ coatings fabricated by other techniques $[6,11,13,16]$, confirming that the coating formed by the electrodeposition and annealing shows high oxidation resistance at high temperatures.

\section{Conclusions}

The $\mathrm{TiAl}_{3}$ oxidation-resistant coating was formed on the TiAl substrate by electrodeposition of $\mathrm{Al}$ from the $\mathrm{DMSO}_{2}$ bath and subsequent annealing. By performing the anodic dissolution of the TiAl substrate in the $\mathrm{DMSO}_{2}$ bath, the surface oxide layer of the TiAl substrate could be removed, and thereby the Al layer could be electrodeposited on the bare surface of TiAl substrate. As a result, a dense, uniform Al layer with good adhesion to the substrate could be obtained. Annealing of the TiAl substrate with the electrodeposited $\mathrm{Al}$ layer at 650,700 and $1000{ }^{\circ} \mathrm{C}$ in vacuum generated the $\mathrm{TiAl}_{3}$ layer. However, a part of the $\mathrm{Al}$ layer remained unreacted after one-hour annealing at $650{ }^{\circ} \mathrm{C}$. The annealing at $700{ }^{\circ} \mathrm{C}$ yielded a single layer of $\mathrm{TiAl}_{3}$, while a multilayer of $\mathrm{TiAl}_{3} / \mathrm{TiAl}_{2}$ emerged by the annealing at $1000{ }^{\circ} \mathrm{C}$. The $\mathrm{TiAl}_{3}$ layer formed through the above process was demonstrated to work as an oxidation-resistant coating at high temperatures.

\section{Acknowledgements}

The authors thank Mr. Teruyoshi Unesaki and Mr. Kenji Kazumi for their help with the SEM and EDX observations; and Prof. Haruyiki Inui (Kyoto Univ.) for providing the TiAl ingot. 


\section{References}

[1] M. Yamaguchi, H. Inui, K. Ito, Acta Materialia 48/1 (2000) 307.

[2] F. Appel, U. Brossmann, U. Christoph, S. Eggert, P. Janschek, U. Lorenz, J. Mullauer, M. Oehring, J.D.H. Paul, Advanced Engineering Materials 2/11 (2000) 699.

[3] H. Clemens, H. Kestler, Advanced Engineering Materials 2/9 (2000) 551.

[4] S. BECKER, M. SCHUTZE, A. RAHMEL, Oxidation of Metals (1993) 93.

[5] K. LUTHRA, Oxidation of Metals (1991) 475.

[6] V. Gauthier, F. Dettenwanger, M. Schutze, V. Shemet, W. Quadakkers, Oxidation of Metals (2003) 233.

[7] C.G. Zhou, H.B. Xu, S.K. Gong, K.Y. Kim, Materials Science and Engineering a-Structural Materials Properties Microstructure and Processing 341/1-2 (2003) 169.

[8] L. Niewolak, V. Shemet, A. Gil, L. Singheiser, J.W. Quadakkers, Advanced Engineering Materials 3/7 (2001) 496.

[9] D.Q. Wang, Z.Y. Shi, Y.L. Teng, Applied Surface Science 250/1-4 (2005) 238.

[10] Z.G. Zhang, X. Teng, H.F. Xiang, Y.G. Sheng, X.J. Zhang, High Temperature Materials and Processes 28/1-2 (2009) 115.

[11] Z.G. Zhang, X. Teng, Y.L. Mao, C.X. Cao, S.J. Wang, L. Wang, Oxidation of Metals 73/3-4 (2010) 455.

[12] N. Mizuta, K. Matsuura, M. Ohno, Y. Miyamoto, S. Kirihara, Journal of Japan Institute of Light Metals 58/12 (2008) 656.

[13] Z.W. Li, W. Gao, M. Yoshihara, Y.D. He, Materials Science and Engineering a-Structural Materials Properties Microstructure and Processing 347/1-2 (2003) 243.

[14] C. Leyens, M. Peters, W.A. Kaysser, Surface \& Coatings Technology 94-5/1-3 (1997) 34.

[15] M.S. Chu, S.K. Wu, Surface \& Coatings Technology 179/2-3 (2004) 257.

[16] M.S. Chu, S.K. Wu, Acta Materialia 51/11 (2003) 3109.

[17] S. Tomohiro, Y. Takahiro, W. Takehiko, Y. Atsushi, Surface \& Coatings Technology 205 (2011) 3900.

[18] T. Jiang, M.J.C. Brym, G. Dube, A. Lasia, G.M. Brisard, Surface \& Coatings Technology 201/14 (2007) 6309.

[19] T. Hirato, J. Fransaer, J.P. Celis, Journal of the Electrochemical Society 148/4 (2001) C280.

[20] J.K. Chang, S.Y. Chen, W.T. Tsai, M.J. Deng, I.W. Sun, Electrochemistry Communications 9/7 (2007) 1602. 
[21] C.C. Yang, Materials Chemistry and Physics 37/4 (1994) 355.

[22] T. MORIKAWA, N. Takuo, Y. Masayuki, Journal of The Surface Finishing Society of Japan 58/5 (2007) 267.

[23] L. Legrand, A. Chausse, R. Messina, Journal of the Electrochemical Society 145/1 (1998) 110.

[24] M. Ueda, D. Susukida, S. Konda, T. Ohtsuka, Journal of the Surface Finishing Society of Japan 54/5 (2003) 363.

[25] G. Chaudhari, V. Acoff, Intermetallics (2010) 472. 
Table 1 Composition of the surface oxidation layer of TiAl substrate generated by heating at $1100{ }^{\circ} \mathrm{C}$ in air.

\begin{tabular}{cccc}
\hline \multirow{2}{*}{ Position $^{\mathrm{a}}$} & \multicolumn{3}{c}{ Content (at. \%) } \\
\cline { 2 - 4 } & $\mathrm{Ti}$ & $\mathrm{Al}$ & $\mathrm{O}^{\mathrm{b}}$ \\
\hline $\mathrm{A}$ & 20.3 & 3.1 & 76.6 \\
$\mathrm{~B}$ & 12.6 & 21.8 & 65.6 \\
$\mathrm{C}$ & 11.2 & 27.7 & 61.1 \\
\hline
\end{tabular}

a: The analyzed positions are indicated in Fig. 8 .

$\mathrm{b}$ : The reliability of the $\mathrm{O}$ contents determined by EDX is low. 


\section{List of figure captions}

Fig. 1: Anodic polarization curve for TiAl substrate in $\mathrm{DMSO}_{2}$ bath.

Fig. 2: SEM images of the surface of the TiAl substrate after anodic dissolution at (a) $0.8 \mathrm{~V}$, (b) $1.4 \mathrm{~V}$ and (c) $2.0 \mathrm{~V}$ for $30 \mathrm{C} \mathrm{cm}^{-2}$ in $\mathrm{DMSO}_{2}$ bath. The $\mathrm{Al}$ contents of points $\mathrm{A}$ and $\mathrm{B}$ marked in the inset of (a) were determined to be 31 and 49 at.\% by EDX, respectively.

Fig. 3: Variation of dissolution current of TiAl substrate with time in $\mathrm{DMSO}_{2}$ bath.

Fig. 4: XRD pattern of electrodeposited Al layer on TiAl substrate.

Fig. 5: SEM image and composition profile of cross-section of electrodeposited $\mathrm{Al}$ layer on $\mathrm{TiAl}$ substrate.

Fig. 6: XRD patterns of samples annealed at (a) $650{ }^{\circ} \mathrm{C},(\mathrm{b}) 700{ }^{\circ} \mathrm{C}$ and (c) $1000{ }^{\circ} \mathrm{C}$.

Fig. 7: SEM images and composition profiles of cross-sections of the samples annealed at (a) $650{ }^{\circ} \mathrm{C}$, (b) $700{ }^{\circ} \mathrm{C}$ and (c) $1000{ }^{\circ} \mathrm{C}$.

Fig. 8: Cross-sectional SEM image of TiAl substrate without $\mathrm{TiAl}_{3}$ coating after oxidation in air at $1100{ }^{\circ} \mathrm{C}$.

Fig. 9: SEM images and composition profiles of cross section of TiAl substrate coated with $\mathrm{TiAl}_{3}$ after oxidation in air at $1100{ }^{\circ} \mathrm{C}$. 


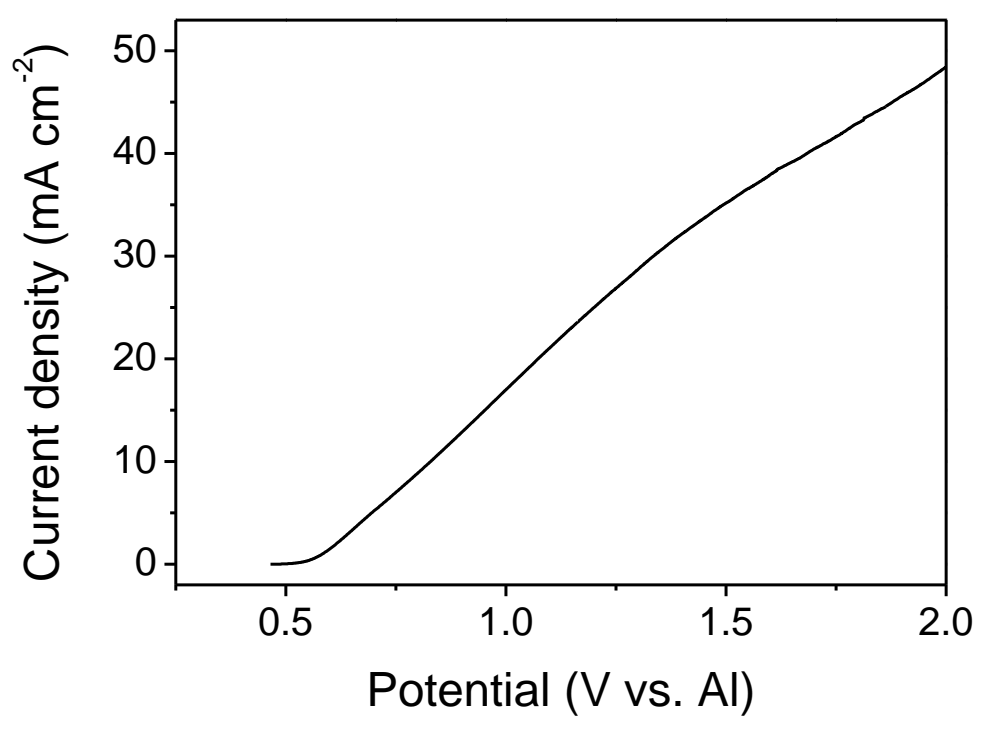

Fig. 1 

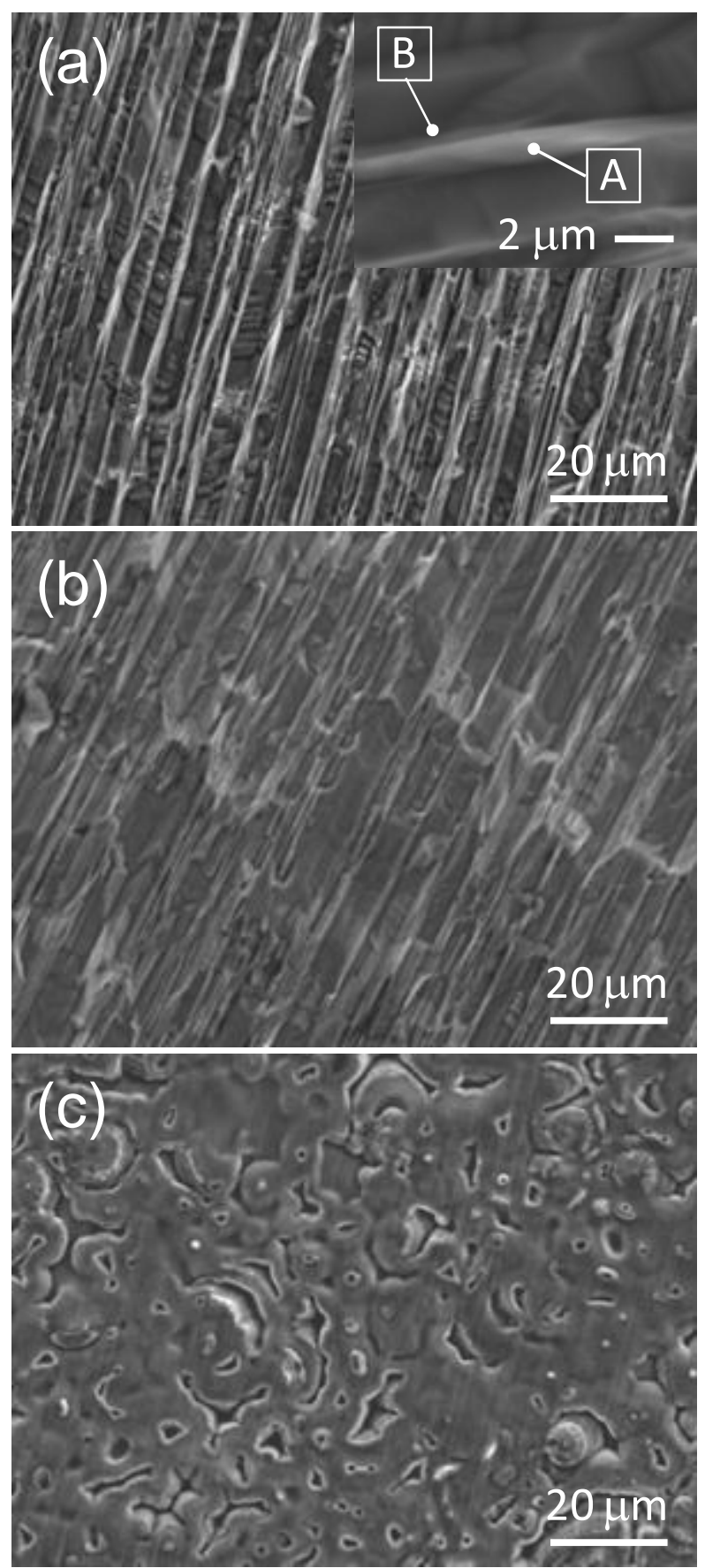

Fig. 2 


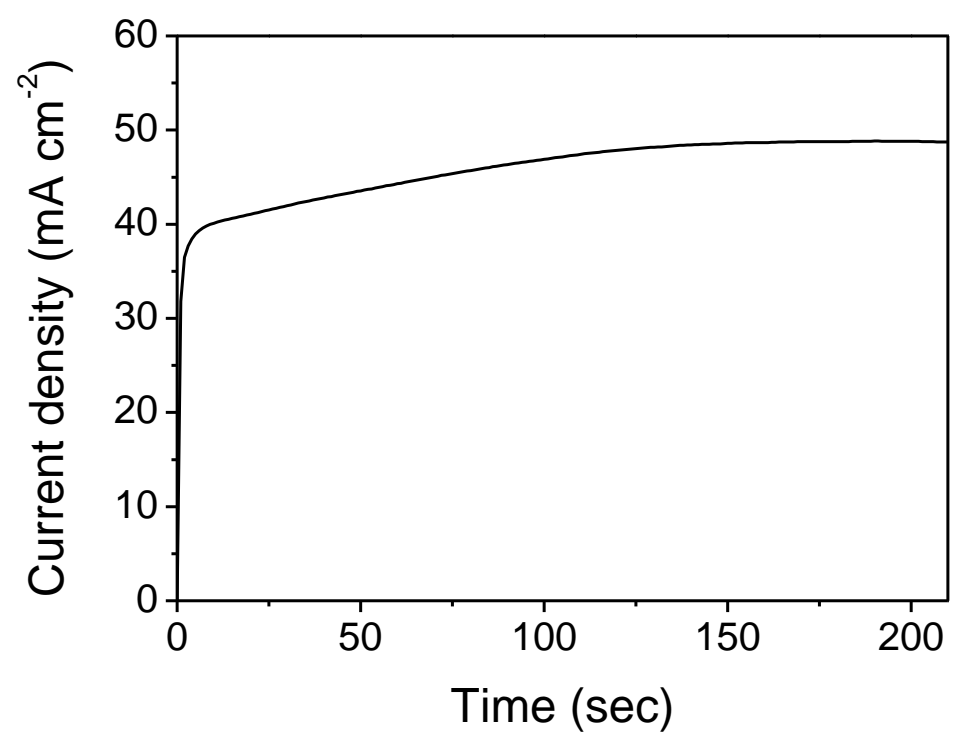

Fig. 3 


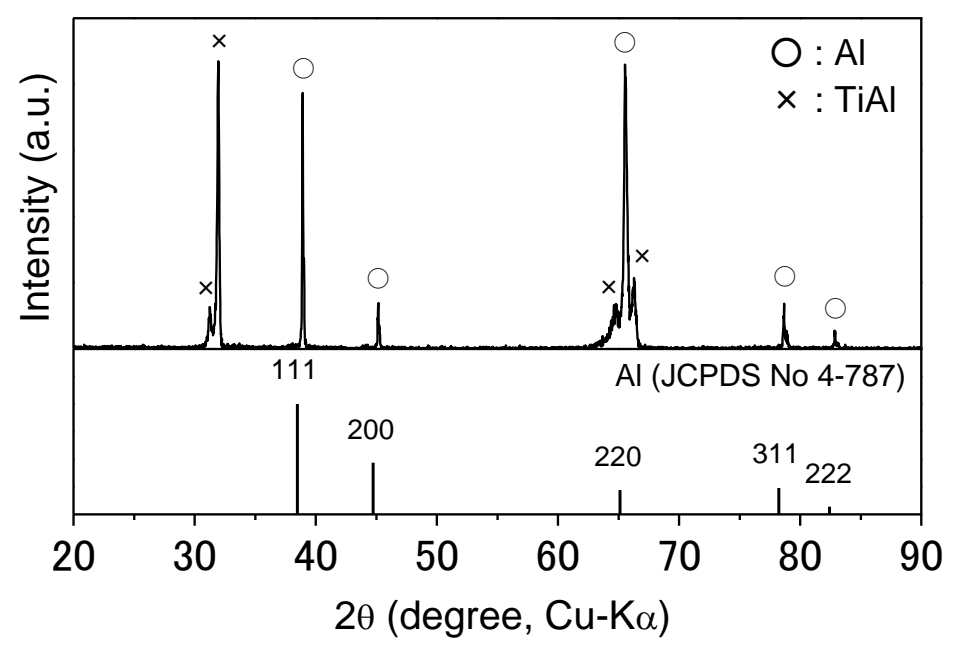

Fig. 4 


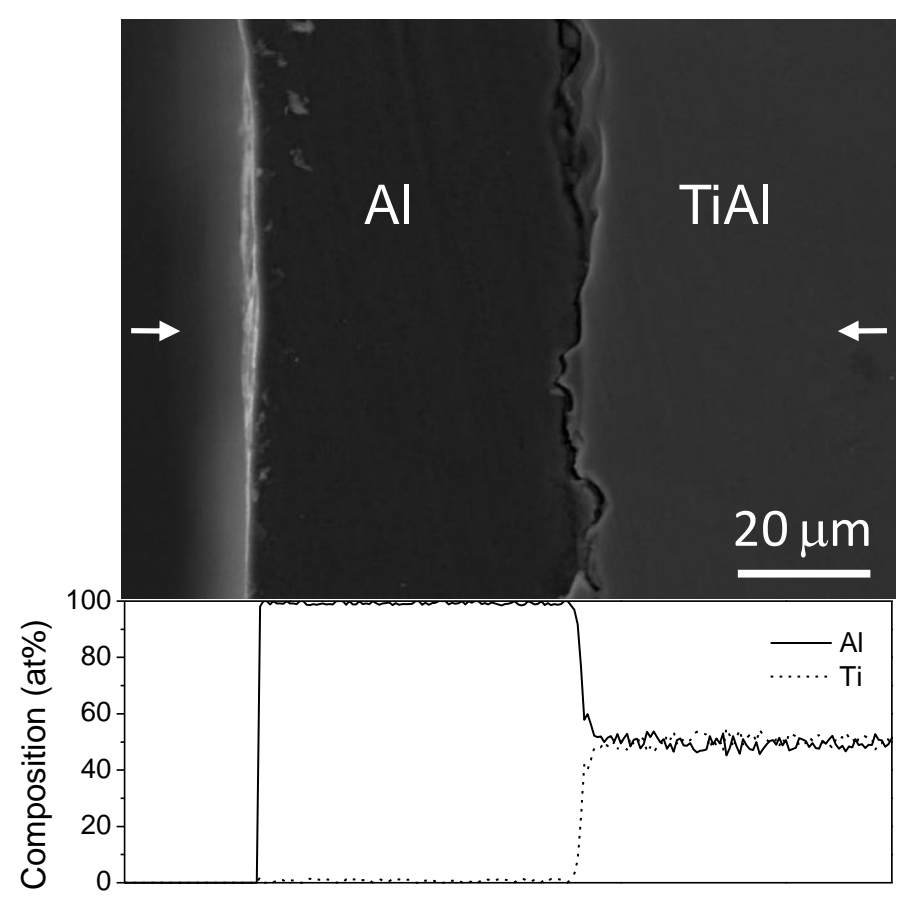

Fig. 5 


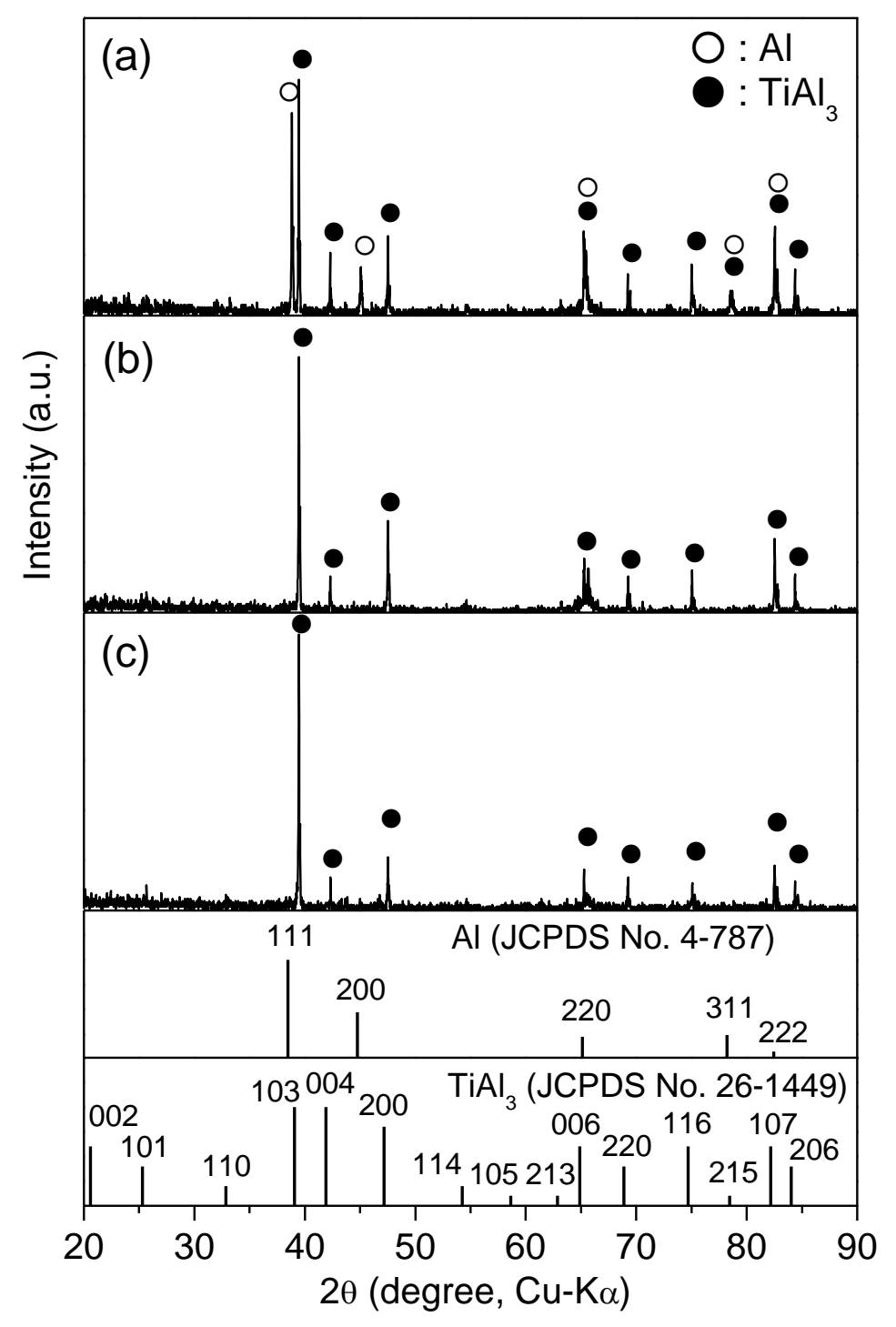

Fig. 6 

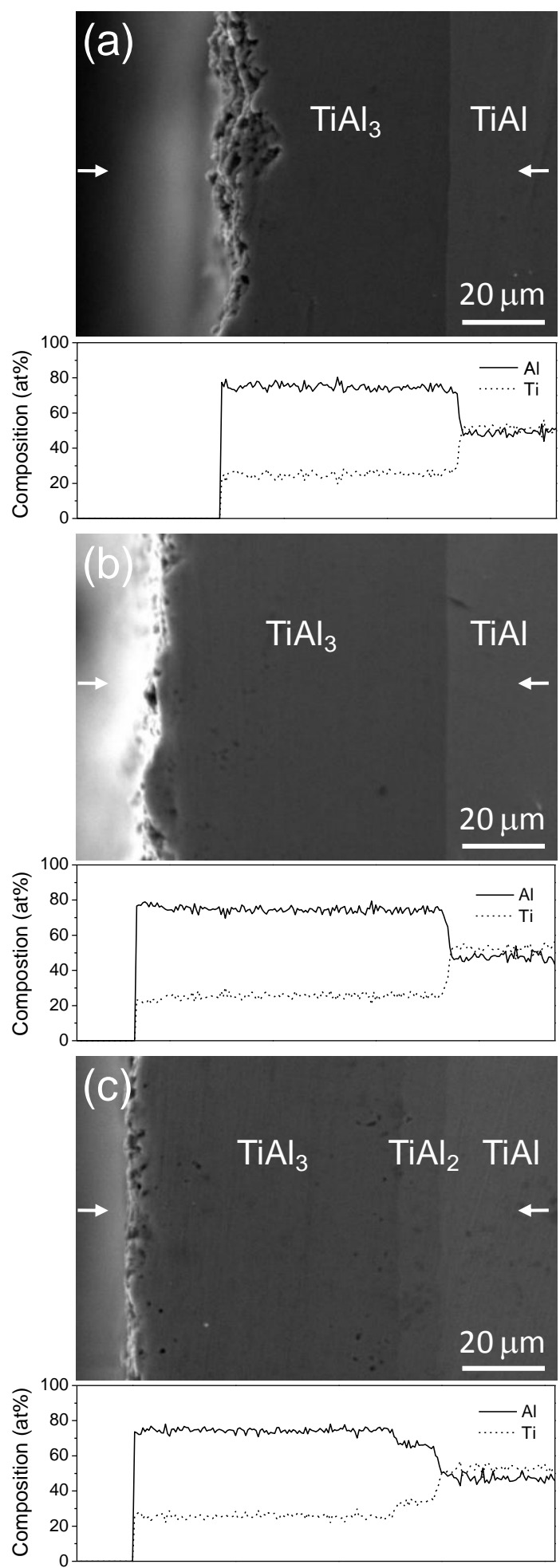

Fig. 7 


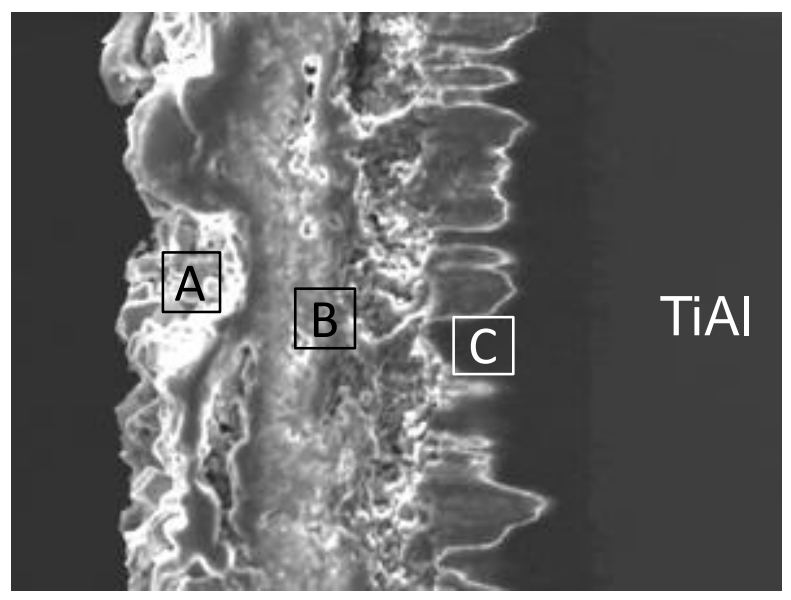

Fig. 8 


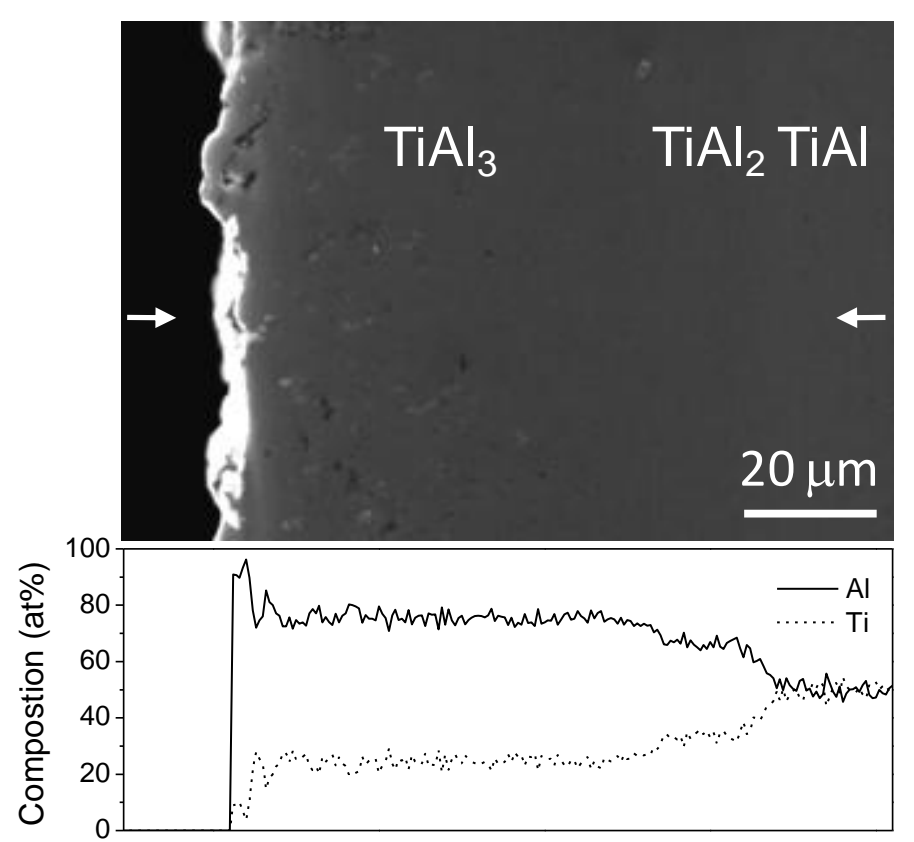

Fig. 9 